\title{
ARTíCULOS DE INVESTIGACIÓN \\ Lo que no es plagio académico: Excepciones desde la perspectiva jurídica
}

\author{
O que não é plágio acadêmico: Exceções do ponto de vista jurídico
}

What is not academic plagiarism: Exceptions from a legal perspective

\author{
Fidias Arias Odón \\ Universidad Católica Andrés Bello, Venezuela
}

\begin{abstract}
RESUMEN Este artículo se propone analizar lo que no es plagio académico mediante el examen de objetos no protegidos por el derecho de autor: ideas, hechos y conocimiento del dominio público, como excepciones previstas en la legislación sobre propiedad intelectual. Si bien es cierto que la apropiación ilícita de una obra es una conducta censurable, no es menos cierto que existen limitaciones en el derecho de autor y, por consiguiente, que hay excepciones que deben ser consideradas en el contexto de la academia. En este sentido, con apoyo en la doctrina del derecho y la jurisprudencia, se exponen los casos de uso lícito de elementos para el trabajo académico, como la utilización de ideas, la referencia a hechos públicos y, en general, el empleo de conocimientos del dominio público. Además, se precisan los requisitos del derecho de cita, así como casos concretos en los que no es obligatorio citar a un autor en particular. Por último, se explica lo que no es plagio académico y se propone una redefinición del concepto.
\end{abstract}

PALABRAS CLAVE Plagio académico, derecho de autor, ideas, hechos, conocimiento del dominio público.

RESUMO Este artigo tem como objetivo analisar o que não é plágio acadêmico por meio do exame de objetos não protegidos por direitos autorais: ideias, fatos e conhecimentos de domínio público, como exceções previstas na legislação sobre propriedade intelectual. Se é verdade que a apropriação ilícita de uma obra é conduta condenável, não é menos verdade que há limitações nos direitos autorais e, portanto, há exceções que devem ser consideradas no contexto acadêmico. Nesse sentido, com respaldo da doutrina do direito e da jurisprudência, expõem-se casos de uso lícito de elementos para o trabalho acadêmico, como o uso de ideias, a referência a eventos públicos e, em geral, o uso de conhecimentos da domínio público. Além disso, são especificados os requisitos 
do direito de citar, bem como os casos específicos em que não é obrigatória a citação de um determinado autor. Por fim, explica-se o que não é plágio acadêmico e propõe-se uma redefinição do conceito.

PALAVRAS-CHAVE Plágio acadêmico, direitos autorais, idéias, fatos, conhecimento do domínio público.

ABSTRACT The purpose of this article was to analyze what is not academic plagiarism by examining objects not protected by copyright: ideas, facts and knowledge of the public domain as exceptions provided for in intellectual property legislation. While it is true that the unlawful appropriation of a work is reprehensible conduct, it is no less true that there are limitations in copyright and therefore there are exceptions that must be considered in the context of academia. In this sense, with support in the doctrine of law and jurisprudence, the cases of licit use of elements for academic work are exposed, such as, the use of ideas, the reference to public facts and in general, the use of knowledge of the public domain. In addition, the requirements of the right of citation are specified, as well as specific cases in which it is not mandatory to quote a particular author. Finally, what is not academic plagiarism is explained and a redefinition of this concept is proposed.

KEYWORDS Academic plagiarism, copyright, ideas, facts, knowledge of public domain.

\section{Introducción}

A lo largo de la historia, la copia no autorizada o apropiación indebida de una obra ajena ha sido un acto censurable y sancionable conocido como plagio. Este puede manifestarse tanto en creaciones materiales como intelectuales: artísticas, científicas y literarias. Una categoría específica de plagio es la que tiene lugar en el medio académico, donde la producción de conocimiento es una función esencial. No obstante, como en todo hecho ilícito, para que se afirme la presencia de plagio en el contexto universitario es necesario que se cumplan una serie de supuestos y se compruebe la falta. De lo contrario, se estaría ocurriendo en una falsa acusación o denuncia falsa, probablemente debido al desconocimiento de lo que no es plagio y de las excepciones señaladas en la legislación sobre derecho de autor.

En este sentido, el objetivo de este trabajo es analizar lo que no es plagio académico mediante el examen de objetos no protegidos por el derecho de autor, como las ideas, los hechos y el conocimiento del dominio público. Para el logro de este objetivo, se hizo una exhaustiva investigación documental basada en el análisis de la literatura especializada sobre propiedad intelectual y, específicamente, sobre el tema del plagio académico.

Asimismo, se consultaron las leyes sobre la materia actualmente vigentes en varios países de Latinoamérica, y la jurisprudencia generada en torno a hechos o casos 
concretos en virtud de lo expresado por Álvarez Undurraga (2014: 47): «El objeto del conocimiento en las ciencias jurídicas son los hechos, las normas y los valores. El investigador jurídico estudia el mundo objetivo y real donde operan las normas».

\section{La jurisprudencia en materia de derecho de autor}

El análisis de jurisprudencia consiste en un examen interpretativo de los elementos constitutivos de las sentencias que, en torno a una materia jurídica, han sido dictadas por altos tribunales de un país. La jurisprudencia en materia de derecho de autor es sumamente extensa. En consecuencia, para los efectos de este artículo se han considerado algunos casos recientes y emblemáticos resueltos por altos tribunales de España, Colombia y Estados Unidos, en lo que concierne, particularmente, a la protección de obras literarias y del ámbito académico.

Específicamente, para el análisis de los casos serán considerados los siguientes elementos: antecedentes de hecho que originan el caso, peticiones de las partes, problema jurídico principal, decisiones que dicta el Tribunal y motivación para decidir.

\section{Sentencia 778/2012 del 27 de diciembre de 2012 del Tribunal Supremo de España}

Como antecedentes del hecho, María Ángeles, la demandante, denunció el plagio de su tesis, mientras que Ramón, el demandado, alegó la creación de su obra antes de que la demandante la terminara y depositara, argumento que utilizó para su apelación. Esto quiere decir que el itinerario procesal se inició con la demanda por plagio de tesis en primera instancia, ante la que el demandado interpuso un recurso en una segunda instancia. Entre las peticiones de la parte demandante, figuró el pago de indemnización por el daño moral causado.

El problema jurídico principal se refirió a la infracción a los derechos de propiedad intelectual consagrados en el texto refundido de la Ley de Propiedad Intelectual. La decisión o fallo del Tribunal desestimó el recurso interpuesto por el demandado y lo instó a pagar la indemnización correspondiente. La motivación para decidir se basó, en primera instancia, en la falta al artículo 1 de la Ley de Propiedad Intelectual $y$, en segunda instancia, en la insuficiencia de pruebas de la existencia previa de la obra por parte del demandado, lo que preserva el carácter original de la obra plagiada perteneciente a la demandada. En este caso, es importante destacar que el magistrado no desestimó la existencia de la obra como prueba, pero no se pudo constatar que existiese antes que la tesis depositada por la demandante. A continuación, se presenta un fragmento textual de la sentencia emitida por el Tribunal Supremo de España, Sala Primera de lo Civil:

El precepto supuestamente infringido, el artículo 1 de la Ley de Propiedad Intelectual, prevé que «la propiedad intelectual de una obra literaria, artística o científica 
corresponde al autor por el solo hecho de su creación». En nuestro caso, el trabajo del demandado, que de reunir el carácter de original tendría la consideración de una obra literaria (artículo 10.1 de la Ley de Propiedad Intelectual), cuyo contenido puede ser literario, científico o artístico, debe entenderse que nace, como objeto de protección, desde su creación, sin que deba condicionarse a su divulgación, publicación, inscripción en el Registro General de la Propiedad Intelectual o a cualquier otra formalidad. No obstante, en cualquier caso es necesario acreditar la existencia de la obra, entendida no como un conjunto de ideas o de información que el autor pudiera tener en su mente, sino en la medida en que consta exteriorizada "por cualquier medio o soporte, tangible o intangible» (artículo 10.1 de la Ley de Propiedad Intelectual).

\section{Sentencia 20/2020 del 16 de enero de 2020 del Tribunal Supremo de España}

Concretamente, los hechos se resumen en el plagio de algunos epígrafes de la tesis doctoral del demandante Miguel Ángel por parte de su tutor o director de tesis, Juan Enrique. El itinerario del caso comienza en una primera instancia, en la que se emite sentencia condenatoria y, luego, en una segunda instancia, se introduce el recurso de casación. Como petitorio, el demandante exige un pago por indemnización del daño moral causado.

$\mathrm{Al}$ igual que el caso anterior, el problema jurídico principal se refiere a la infracción a los derechos de propiedad intelectual. La decisión del Tribunal condena al demandado a pagar una indemnización por el daño moral causado a la parte actora y se desestima el recurso de casación interpuesto por el demandado. La motivación para decidir se fundamenta en la reproducción literal de los epígrafes, "por lo que no cabe escudarse en que las ideas transmitidas constituían un conocimiento común para negar originalidad a la obra parcialmente reproducida. El plagio se verifica con la reproducción literal del texto» (Tribunal Supremo de España, Sala Primera de lo Civil, STC 20/2020 del 16 de enero 2020).

\section{Sentencia 61883 del 19 febrero de 2019 de la Dirección Nacional de Derecho de Autor de Colombia}

Los hechos son los siguientes: la demandante CCD denunció el plagio de su tesis de maestría por parte de WBM, quien publicó un artículo que constituía una copia casi textual de un apartado. Como pretensión, la demandante solicitó un pago por el daño ocasionado. El problema jurídico radicó en la violación al derecho de autor, que por paternidad de la obra le correspondía a la demandante. En este caso, se infringieron preceptos contemplados en la Ley 23 de 1982 sobre Derechos de Autor. El fallo condenó al demandado a reparar los daños patrimoniales y morales causados mediante el pago establecido en la sentencia. 
Los argumentos que motivaron la decisión fue la apropiación indebida de fragmentos de la tesis sin la autorización de la autora del texto original por parte del demandado, quien asumió la autoría del trabajo como propia. Además, según consta en expediente, el demandado conocía previamente el contenido de la tesis, dado que, durante el proceso de investigación, este sostenía una relación con la autora. Otro argumento considerado por el juez de la causa fue que los hechos ocurrieron en el contexto académico universitario, donde ante todo debe prevalecer la ética y honestidad intelectual.

\section{Sentencia 537 US 186 de 2003 (Eldred contra Ashcroft) de la Corte Suprema de Estados Unidos}

El litigio emprendido por Eric Eldred demandó la inconstitucionalidad de la Ley de Extensión del Término de los Derechos de Autor ante el fiscal general John Ashcroft. El demandante argumentó que la ley excedía las competencias del Congreso para legislar con respecto a los plazos relativos a la protección de las obras. No obstante, también planteó que la ley atentaba contra la libertad de expresión consagrada en la primera enmienda. En este sentido, contraria a las pretensiones de Eldred, la sentencia refutó la supuesta infracción a la primera enmienda y resolvió la controversia con respecto a la «dicotomía idea/expresión», como se aprecia en la siguiente cita:

Además de estimular la creación y publicación de nuevas expresiones, la legislación sobre derecho de autor distingue entre ideas y expresión, y hace que solo esta última sea objeto de protección. Específicamente, en el Código de Leyes de los Estados Unidos, título 17, capítulo 1, artículo 102 (b), se establece: En ningún caso la protección de los derechos de autor para una obra original se extiende a ninguna idea, procedimiento, proceso, sistema, método de operación, concepto, principio o descubrimiento, independientemente de la forma en que se describa: explicado, ilustrado o incorporado en dicho trabajo. Esta dicotomía idea/expresión logra un equilibrio de definición entre la primera enmienda y la Ley de Derechos de Autor, al permitir la libre comunicación de hechos mientras se protege la expresión del autor. Debido a esta distinción, cada idea, teoría y hecho en una obra protegida por derechos de autor se vuelve instantáneamente disponible para la explotación pública en el momento de la publicación (Corte Suprema de los Estados Unidos, STC 537, 2003).

\section{Comentario}

En general, las sentencias anteriores parten de un principio jurídico fundamental: la protección de la obra, cuya propiedad intelectual se atribuye al autor por el hecho de ser el responsable de su creación. En todos los casos, se debe probar la existencia de dicha obra aun cuando esta no haya sido publicada, difundida o registrada. 
No obstante, la propiedad intelectual tiene sus límites y excepciones referidas a los objetos sin protección, y es por eso que dichas sentencias coinciden en aclarar de forma precisa que únicamente se protege la obra como producto o resultado tangible del trabajo intelectual, particularmente el estilo de expresión en las obras literarias, pero no se resguardan las ideas inmersas en la obra o las que dieron origen a ella.

En lo sucesivo, se desarrollan los objetos no protegidos por el derecho de autor.

\section{Las ideas: Objeto sin protección por el derecho de autor}

Las ideas son un producto de la mente humana referido a la realidad, es decir, son el resultado de procesos intelectuales, como la percepción y la creatividad. De las ideas surgen conceptos que, organizados de manera sistemática, conforman el conocimiento de un área, materia o disciplina.

En el ámbito de la propiedad intelectual y del derecho de autor, existe una clara distinción entre idea y obra, entre la representación mental abstracta e intangible, y el producto concreto, materializado y tangible, caracterizado por una forma o estilo de expresión. Joyce y otros (2016) lo mencionan como la dicotomía idea-expresión.

Ante esta dicotomía, la doctrina jurídica ha optado por promover el amparo de la obra, pero no de la idea que le dio origen, es decir, la legislación sobre propiedad intelectual no resguarda las ideas, sino su forma de expresión (Llopis Nadal, 2019). Así, «ese principio de recepción legislativa universal ha sido explicado por la jurisprudencia en varios países al resolverse que la ideas no implican derechos de propiedad o de exclusividad» (Antequera Parilli, 2010: 127).

En consecuencia, las legislaciones nacionales e internacionales en materia de derecho de autor solo protegen las obras o creaciones artísticas, literarias y científicas, pero quedan excluidas las ideas, como lo expresó el artículo 2 del Tratado de la Organización Mundial de la Propiedad Intelectual (OMPI) sobre Derechos de Autor en 1996: «La protección del derecho de autor abarcará las expresiones, pero no las ideas, procedimientos, métodos de operación o conceptos matemáticos en sí».

La exclusión de las ideas y demás conceptos afines del dominio del derecho de autor, se funda en promover un balance justo y adecuado en los derechos que otorga esta propiedad intelectual. Si el derecho amparara las ideas, se estaría dando al titular de una obra un derecho mucho mayor que la obra en sí, ya que se impediría el desarrollo de obras ulteriores, que podrían ser fruto de la propia expresión del nuevo autor, elaboradas en forma independiente, pero con base en una idea similar. (Palazzi, 2009: 25)

Es importante señalar que, mucho antes de la firma del Tratado de la Organización Mundial de la Propiedad Intelectual, Henri Desbois (1978: 11) ya expresaba la exclusión de la ideas como objeto de propiedad autoral en su obra el Derecho de Autor en Francia: 
Más allá de su ingeniosidad y de que lleven la marca del talento, la propagación y la explotación de ideas expresadas por otro no pueden ser contrariadas por las obligaciones inherentes a los derechos de autor: por esencia y por finalidad son de libre circulación.

Finalmente, queda claro que «solo la composición que consiste en la organización de las ideas y la expresión son objeto de protección» (Maurel-Indart, 2014: 208).

\section{Las ideas en el ámbito científico y académico}

Precisamente, es en el medio académico donde persiste la controversia acerca del derecho sobre las ideas. No obstante, como se demostrará en lo sucesivo, son la legislación en materia de propiedad intelectual, la doctrina y la jurisprudencia las que no solo regulan, sino que también contribuyen a dilucidar el asunto.

Sobre el uso de las ideas en el contexto académico, Toller (2011: 90) ha escrito que «hay también ideas compartidas en general por todos los cultores de una rama del saber. Por esto, quienes las utilizan no incurren en plagio. Se trata simplemente del funcionamiento normal de la vida intelectual en la academia».

Además, como se ha expuesto anteriormente, las ideas están excluidas de protección legal en el ámbito intelectual, con el fin de propiciar el avance de las ciencias y las humanidades. En este sentido, la Corte Suprema de Justicia de Colombia y la Cámara Nacional de Apelaciones en lo Criminal y Correccional de Argentina, citadas por Antequera Parilli (2010: 127), se pronunciaron:

Los conocimientos científicos pertenecen al dominio público [porque] las ideas se esparcen y propagan sin prescripción alguna y el derecho de autor protege solo la forma, el modo de expresión y deja dentro del dominio público la idea, la cual integra el fondo común de la humanidad.

Esa exclusión se justifica porque, a partir de las mismas ideas, se pueden crear diversas obras, cada una de ellas con su propia personalidad, de suerte que su monopolio frenaría el desarrollo de la literatura, las artes y la investigación científica (Antequera Parilli, 2010: 127).

\section{Jurisprudencia sobre las ideas en relación con el derecho de autor}

Un caso ocurrido el 2005, en España, es la demanda interpuesta por Tiempo Real, S.A., como titular de la obra «Controlador Pid», contra Don Rodrigo, autor de la obra «Sistemas de Medida y Regulación», argumentando que esta última constituye un plagio (Juzgado de lo Mercantil 2 de Madrid, STC del 14 de noviembre de 2005).

La sentencia basada en la no protección de las ideas y en la diferencia en la forma de expresión, concluye que: 
El Juzgado de lo Mercantil 4 de Madrid desestima la demanda formulada en ejercicio de acciones de vulneración del derecho de autor, no apreciando la existencia de plagio en la obra científico-docente de los codemandados (Juzgado de lo Mercantil 2 de Madrid, STC del 14 de noviembre de 2005).

En la misma materia, un caso emblemático referido a una falsa acusación de plagio es la demanda interpuesta por Patricia Laura Zas contra el filósofo argentino Santiago Kovadloff, en la que alega una supuesta apropiación ilícita de ideas. En este sentido, la Cámara Nacional en lo Criminal y Correccional de Argentina, citada en Cerlalc (2009), sentenció:

Las ideas consideradas no son obras y su uso es libre. No se puede adquirir sobre ellas protección o propiedad alguna, aun cuando sean novedosas. [...] En definitiva, el Tribunal resuelve: Confirmar el auto de fs. $71 / 73$ vta en cuanto dictó el sobreseimiento de Santiago Kovadloff en orden al hecho que se le imputara, con la expresa mención de que la formación del presente sumario en nada afecta el buen nombre y honor de que hubiere gozado con anterioridad (artículo 336, inciso 3, Código Procesal Penal de la Nación Argentina).

En síntesis, la decisión en los casos mencionados se fundamenta en jurisprudencia, y esta, a su vez, en la doctrina jurídica asumida por la Organización Mundial de la Propiedad Intelectual desde 1996, la cual ampara las formas de expresión, pero no las ideas.

\section{Hechos públicos y notorios}

Los hechos se refieren a cualquier acontecimiento o suceso que ocurre en la naturaleza o en la sociedad y, de manera más específica, en el ámbito histórico, político, económico y científico, entre otros. La característica principal de un hecho público y notorio es tanto su amplia difusión como su permanencia en la memoria colectiva. Precisamente, cuando los hechos trascienden y se convierten en información socializada, al igual que las ideas, pasan a integrar parte del dominio público de la humanidad. En consecuencia, carecen de protección legal y nadie puede atribuirse su autoría.

Como expresó Palazzi (2009: 23), «los hechos» que forman parte del conocimiento de la sociedad y están en el dominio público tampoco se amparan por el derecho de autor. Además, el autor advierte que, «por ello, nadie puede apropiarse de la realidad material ni de los sucesos históricos».

Asimismo, según el Convenio de Berna de 1979, en su artículo 2.8, tampoco están amparadas las noticias del día (derivadas de cualquier hecho) «ni los sucesos que tengan el carácter de simples informaciones de prensa» (OMPI, 1979).

En el ámbito científico y académico, los hechos constituyen el objeto de estudio 
de diversas investigaciones y, como se ha dicho, el hecho que da origen al tema de investigación no le pertenece ni es exclusividad de un autor. Entonces, la originalidad y la novedad de futuros estudios basados en un mismo hecho radican en la interpretación particular de cada investigador, en el enfoque metodológico asumido y en el período en el que se obtuvieron los datos, que, por supuesto, varían en el tiempo o de un momento a otro.

Por ejemplo, son muchos los estudios que se han realizado sobre la violencia, basados en múltiples hechos ocurridos y comunicados en una sociedad, por lo que es normal la presencia de elementos coincidentes. No obstante, el carácter original e innovador estaría en el uso de un método de investigación diferente a los tradicionales, en el análisis de los resultados y conclusiones, en las que se imprime la perspectiva e interpretación del autor.

\section{Jurisprudencia en materia de los hechos públicos y el derecho de autor}

Los pasajes de sentencias que se referirán a continuación aparecen citadas originalmente por Palazzi (2009: 24), quien destaca sentencias de la Cámara Nacional de Apelaciones en lo Civil de Argentina correspondientes a 1999 y 2005:

La ley solo protege la forma, el modo de expresión, la aplicación del tema, la marca de individualidad, es decir, lo que da a la obra el carácter personal, original, lo que revela el poder creador del autor.

No es tutelable - en cambio - la realidad material en que se ha inspirado o de la cual el autor ha hecho objeto de su expresión, porque esa realidad no ha sido creada por él.

Sobre el mismo asunto, Palazzi (2009: 23) señala que «los hechos — al igual que las ideas- están en el dominio público y son libremente apropiables».

Por último, Morales Montes (2016: 117) concluye que «nadie es dueño de la idea, de una determinada temática o de los simples hechos o sucesos».

\section{Dominio público material e intelectual}

En general, el dominio público se refiere al conjunto de creaciones de la humanidad, tanto materiales (edificaciones, vías de comunicación terrestre y bienes muebles) como inmateriales (ideas, información, obras literarias y científicas) que no están amparadas en la legislación sobre derechos de autor. En consecuencia, su uso y reproducción está libre y exento de pago.

Específicamente, el dominio público intelectual agrupa ideas, conocimientos, información y obras artísticas, literarias y científicas, que, por vencimiento de los derechos patrimoniales de autor o por su extensa socialización y autoría indeterminada, pasan a ser del fondo común de la humanidad. Además, forman parte del dominio 
público intelectual los conocimientos científicos y los conceptos genéricos en cualquier disciplina.

En este sentido, Joyce y otros (2016: 116) expresan:

Una vez que un autor revela su trabajo al público, cualquier idea contenida en la obra es liberada al dominio público y este debe quedar satisfecho con la protección, únicamente, de la forma específica con la cual expresó esas ideas.

Por otra parte, la Recomendación sobre la Promoción, Uso del Multilingüismo y Acceso Universal al Ciberespacio de la Unesco (2003) agrega a la definición de información del dominio público «los datos de carácter público y la información oficial producidos y difundidos voluntariamente por los gobiernos o las organizaciones internacionales».

Como consecuencia, los datos de dominio público pueden ser divulgados y utilizados para producir nuevos conocimientos sin restricción alguna. No obstante, cuando se usan datos estadísticos oficiales sobre la población o la salud de un país, aun cuando sean del dominio público, se reconocerá la autoría por parte del organismo responsable.

Es importante advertir que las ideas y conceptos no deben confundirse con el dominio público intelectual. Estos son solo algunos de los elementos que lo integran, pero el dominio público abarca mucho más que ideas, ya que también lo constituyen las obras artísticas, los hechos, los sucesos históricos, los conocimientos científicos y la información.

\section{El conocimiento del dominio público}

A diferencia de algunas obras anónimas que pueden formar parte o no del dominio público, existen contenidos básicos de ciertas disciplinas cuya creación no se puede atribuir a un autor conocido o desconocido en particular. En estos casos, se trata de una acumulación de conocimientos producto de múltiples contribuciones durante el desarrollo de la sociedad.

Como sentenció la Corte Suprema de Justicia de Colombia en 1990 (Antequera Parilli, 2010: 127), «los conocimientos científicos pertenecen al dominio público [por cuanto] las ideas se esparcen y propagan sin prescripción alguna».

Por ejemplo, conceptos genéricos como los de educación, economía y sociedad pueden ser de autoría indeterminada. En todo caso, lo que aportan los autores son definiciones en las que se pone de manifiesto su estilo o forma de expresión particular, pero dichos autores no son los creadores del concepto. Luego, como expresara Arce Gómez (2009: 63), «una definición concreta de justicia emitida por un autor sí puede ser objeto de plagio». 


\section{Derecho de cita y el derecho a no citar}

El derecho de cita es la potestad que tiene un autor para utilizar, de forma lícita, fragmentos de obras publicadas y divulgadas por otros autores para la elaboración de obras propias, siempre con fines pedagógicos o científicos, y reconociendo la autoría de la obra citada, pero sin requerimiento de pago o autorización.

El derecho de cita está contemplado en varias legislaciones, entre ellas la de Argentina (1933), Chile (1970), Colombia (1982), Venezuela (1993), México (1996) y Perú (2014).

Existe total acuerdo en que, al tomar elementos de una obra original, obligatoriamente se debe conceder el crédito al autor de dicho trabajo. Sin embargo, no todas las obras acerca de un tema son originales ni de calidad para ser consideradas y citadas en una investigación o trabajo académico.

Muchas obras, al ser evaluadas rigurosamente, dejan ver que se trata de una compilación de fuentes secundarias y terciarias sin aporte novedoso del autor. Además, existen otros criterios de calidad que deben ser tomados en cuenta a la hora de seleccionar y citar una fuente, por ejemplo, que haya sido sometida a evaluación o arbitraje, que esté publicada en una revista indexada de prestigio, y que haya tenido algún impacto en comunidades científicas y académicas.

La simple disponibilidad o visibilidad de un texto en internet no es garantía de pertinencia para un estudio científico. Por otra parte, también puede ocurrir que a determinados autores se les atribuya erróneamente la autoría de contenidos que no son resultado de sus investigaciones. En estos casos, lo conveniente es acudir a las fuentes originales o primarias.

En función de lo anterior, citar será obligatorio cuando se trate de una obra original divulgada, pertinente y previamente evaluada para su publicación, de la que se han extraído contenidos porque aportan y sustentan un trabajo. Por obra original en el ámbito científico y académico, se entenderán aquellos trabajos de investigación (informes, tesis, libros o artículos arbitrados) que generan nuevos datos, resultados, conclusiones o teorías, es decir, nuevos conocimientos como aporte innovador a la ciencia y que, además, reflejen el estilo expresivo y la creatividad del autor. Específicamente sobre los aspectos de la originalidad, Antequera Parilli (2010: 142) menciona que:

Cuando se afirma que para la existencia del plagio es menester la apropiación de elementos originales propios del autor usurpado, se quiere decir que el derecho de autor protege solamente aquello que expresa la personalidad del creador, de modo que la apropiación debe versar sobre la forma de expresión o la estructuración de los contenidos que reúnan el requisito de la originalidad.

También es obligatorio citar si se utilizan elementos de obras, datos estadísticos o información de autores determinados, aun cuando formen parte del dominio públi- 
co, sea por caducidad de los derechos patrimoniales sobre la obra ya que «los derechos morales en los países de tradición jurídica latina son perpetuos, inalienables e intransferibles» (Astudillo Gómez, 2006: 249), o por ser de libre disponibilidad. Por ejemplo, deben ser citados, si de estos se ha tomado algún extracto, los autores de obras clásicas, así como los de artículos científicos arbitrados que se encuentren en plataformas de acceso abierto.

En este sentido, «hay que recordar que el hecho de pertenecer una obra al dominio público no significa la extinción de los derechos morales» (Schmitz Vaccaro, 2009: 353), y es precisamente a través de una correcta cita como se reconoce un derecho moral del autor sobre su obra.

Por consiguiente, toda cita debe cumplir las siguientes condiciones de legalidad (Arce Gómez, 2009):

- La cita debe ser de fragmentos de una obra y de extensión moderada, de modo que el trabajo que se realiza muestre un aporte de su autor y no sea una reproducción total de palabras de otros autores, aun cuando hayan sido citados.

- Se utilizará para analizar, comentar, sustentar o reforzar un planteamiento, o para lo contrario, refutarlo, cuestionarlo o criticarlo.

- El contenido de la cita debe ajustarse al contexto y no deberá ser alterado o tergiversado.

- Debe emplearse con fines educativos o de investigación.

- La cita debe extraerse de una obra publicada y difundida. No son lícitas las citas de obras inéditas.

- Obligatoriamente se debe mencionar la fuente u obra citada, así como su autor en la referencia correspondiente.

Por otra parte, aun cuando existen límites para el uso de obras científicas, como la obligación que tiene el usuario de reconocer la autoría de una obra original consultada mediante la citación de la misma, esto no ocurre en todos los casos, ya que existen conceptos cuya autoría es desconocida y han sido extensamente difundidos en una comunidad académica, por lo que es posible dejar de citar a uno o varios autores en particular que hayan trabajado el mismo tema sin incurrir en plagio académico.

En síntesis, no será necesario citar en los siguientes casos:

- Cuando se trate de conocimiento del dominio público sin autoría determinada.

- Si se reseñan conocimientos ampliamente compartidos por una comunidad científica o académica. Por ejemplo, para expresar que la cultura provee los medios para la adaptación de los seres humanos a su ambiente no se requiere acudir a una cita, por cuanto se trata de una afirmación universalmente soste- 
nida por los antropólogos (The Harvard College, 2016).

- Al definir conceptos básicos en una determinada disciplina, por ejemplo, en pedagogía: educación, didáctica, enseñanza y aprendizaje, entre otros.

- Obras poco originales o artículos divulgativos de baja calidad y no arbitrados, aunque aborden el mismo tema sobre el que investigamos.

En consecuencia: dejar de citar una fuente documental relacionada con el tema de investigación no necesariamente implica plagio o egoísmo por parte del investigador, porque dicha fuente, además de ser primaria y pertinente, debe cumplir con otros requisitos, como ser novedosa, de calidad, y que provenga de un autor con altas condiciones éticas dentro del medio académico (Arias Odón, 2019: 20).

En cuanto a las normas y sistemas de citas, se destacan:

- Sistema autor-fecha, mayormente utilizado en ciencias sociales y humanidades, que ha sido difundido internacionalmente por la American Psychological Association (APA). Básicamente, consiste en incorporar en el texto, inmediatamente después de la cita, el apellido del autor y el año de publicación de la obra entre paréntesis, obviando las notas al pie de página para referencias.

- Normas de Vancouver, generalmente usadas en ciencias naturales, ciencias de la salud y áreas tecnológicas. Este sistema se distingue de las Normas APA fundamentalmente en el orden de presentación de los elementos en las referencias.

- La norma ISO 690:2010(E), muy utilizada en el campo del derecho y de las ciencias jurídicas, se caracteriza por relacionar, mediante un número, la cita incorporada al texto con la referencia correspondiente, que puede ser ubicada al pie de página o en la lista de referencias al final del capítulo o de la obra.

- Las normas de estilo Chicago-Deusto que admiten el uso excluyente y no combinado de cualquiera de los dos principales sistemas antes mencionados: el sistema de referencias al pie de página y el sistema autor-fecha.

\section{Lo que no es plagio académico}

El tema del plagio académico ha sido tratado ampliamente desde la mera óptica de las instituciones científicas y universitarias hasta la perspectiva de carácter jurídico, por sus implicaciones legales en cuanto a derechos morales y patrimoniales se refiere.

Particularmente, sobre el plagio desde un enfoque académico, se destacan las notas de autores como Alonso-Arévalo (2017), Astudillo Gómez (2006), Becerra Ramírez (2012), Eco (2010), Ruipérez y García-Cabrero (2016), Sabino (2009) y Sierra Bravo (2003).

En este sentido, se incurre en plagio académico cuando existe: 
Copia textual, fiel o exacta de un determinado texto, con suplantación u omisión del autor del mismo. Esta copia puede ser total o parcial.

Paráfrasis incorrecta mediante el cambio o sustitución de solamente algunas palabras de un texto, apropiándose de elementos sustanciales y estructurales de la obra reconocida como original de un autor, sin citar al mismo.

Incumplimiento de normas de publicación o de citación propias del medio científico y académico, como, por ejemplo, la falta de comillas en reproducciones textuales de frases o párrafos cortos y omisión de la fuente, al no incorporarla al texto mediante el sistema autor-fecha, al no indicar la referencia al pie de página o mediante otro sistema de citas.

Autoplagio o reproducción total o parcial que hace un autor de su propia obra antes publicada, sin señalar o citar su trabajo anterior. En los casos de uso de párrafos o fragmentos de la obra, este asunto queda corregido cuando se emplea el recurso de la autocita. En situaciones de capítulos u obras completas, debe existir la aclaratoria o advertencia del autor, señalando que el trabajo ha sido publicado con anterioridad.

En síntesis, aun cuando se observa una precisión de los causales que constituyen plagio, no ocurre de igual manera en sentido contrario, es decir, en el medio universitario no hay suficiente claridad acerca de lo que no es plagio académico. De ahí que, con base en la doctrina del derecho y la jurisprudencia, se pretenda analizar las excepciones y supuestos en lo que no se incurre en plagio académico.

En principio, todo trabajo de investigación o de creación intelectual académica se apoya en el carácter acumulativo y sistemático del conocimiento científico, específicamente cuando se consideran trabajos anteriores relacionados o estudios que tiempo atrás desarrollaron el mismo tema (antecedentes de investigación o estudios previos). Por tradición científica, exigencias de la academia y normativas legales, la autoría de todo trabajo consultado debe ser reconocida mediante los sistemas de citación de fuentes establecidos para ello.

Sin embargo, no siempre que se expresa una frase o contenido que no sea creación propia, sin citar a un autor, se incurre en plagio académico (Miranda Montecinos, 2013). En este sentido, con base en los planteamientos del autor mencionado, se precisa que no se comete plagio académico cuando se deja de citar autores sobre:

- Verdades aceptadas universalmente como las Leyes de Newton o el efecto del calor sobre los cuerpos.

- Ideas ampliamente compartidas por miembros de una comunidad científica o académica pertenecientes a una disciplina (Toller, 2011).

- Conocimientos del dominio público en general.

- Hechos públicos y notorios.

- Sucesos de carácter histórico ampliamente divulgados. 
Asimismo, Toller (2011) considera que no se comete plagio académico en los casos que se argumenta la «excepción de insignificancia», entendida como error, inadvertencia, olvido o impericia en el manejo de las técnicas de citación y registro de las referencias.

\section{Jurisprudencia sobre inexistencia de plagio académico}

Un caso de 2015 es el suscitado en Murcia, España, referido a un supuesto plagio de un trabajo final de máster. Esto fue resuelto por el Juzgado de lo Mercantil 2 de Murcia, presentando los siguientes argumentos para decidir:

La mera recogida de datos, muy trabajosa y meritoria para la actora, no constituye la creación de una base de datos, que ni siquiera ha sido aportada a autos, ni confiere derechos de propiedad intelectual sobre ellos. No hay ningún criterio de organización o estructura que suponga una labor intelectual y creativa que goce de originalidad y, por ende, sea susceptible de derecho de propiedad intelectual. La protección que se confiere a la base de datos radica en la originalidad en la presentación, organización, estructura, etcétera, de los datos contenidos. Pero la simple obtención de datos, a través de cuestionarios - entre ellos los cuestionarios aportados como anexos en el trabajo- no es susceptible de derechos de autor. El Juzgado de lo Mercantil 2 de Murcia desestima la acción de protección de derechos de propiedad intelectual al no apreciar plagio en el trabajo de la demandada con respecto al de la demandante (Juzgado de lo Mercantil 2 de Murcia, STC 322/2015 del 30 de diciembre de 2015).

Los supuestos considerados en el caso anterior coinciden con el fondo de las sentencias referidas a continuación y citadas originalmente por Antequera Parilli (2010). Según sentencia de la Corte de Casación italiana, «no existe plagio cuando la imitación se refiere a elementos carentes de originalidad» (Antequera Parilli, 2010: 142)

Asimismo, el autor agrega:

Por ello, la Corte del Distrito Central de California decidió que «los hechos y las teorías históricas se pueden copiar, mientras el demandado no se apropie de la expresión personal del demandante», mientras que el Tribunal de Justicia del Estado de São Paulo resaltó que no hay plagio «cuando semejanzas en pasajes de obras didácticas elementales surgen de la necesidad de una singular participación al principiante de los símbolos y conceptos básicos de la disciplina» (Antequera Parilli, 2010: 142).

Por otra parte, la Suprema Corte de Justicia de la Nación de México, citada también por Antequera Parilli (2010: 142), sentenció que:

No existe el plagio denunciado, si se trata de argumentos diferentes, aunque el tema sea el mismo, porque lo que la ley prohíbe es la reproducción de una obra [...] no que sobre el mismo tema se ejecuten otros trabajos. 
En igual sentido, la Cámara Nacional en lo Civil y la Cámara Nacional en lo Criminal de Argentina, citadas por Palazzi (2009: 8), sentencian respectivamente que:

Aunque dos obras se desarrollen sobre esa misma base, el plagio no se configura, pues la idea no tiene autor, a nadie pertenece en exclusividad ni persona alguna puede ejercer un monopolio sobre ella.

Es posible escribir una obra sobre la misma idea, o mencionar una idea en una conferencia, aunque sea de otra persona, o directamente ponerla en práctica sin infringir la ley de propiedad intelectual.

\section{Un caso famoso de falsa acusación de plagio}

Como hemos visto, «las acusaciones de plagio pueden ser utilizadas como arma de chantaje, pero también como arma de venganza» (Maurel-Indart, 2014: 184).

La cita refleja una penosa situación que se ha presentado en diversos medios: literario, político, científico y académico. Si bien es cierto que algunos casos de plagio han sido probados con las respectivas consecuencias legales, no es menos cierto que también se han presentado falsas e improcedentes acusaciones que no pasan de ser simples rumores emitidos con la intención de dañar la imagen del supuesto involucrado. En este sentido, a continuación se presenta un caso relevante.

El médico cirujano Robert Bárány hizo aportes significativos a la investigación de la anatomía y la función auditiva. En 1914, Bárány obtuvo el Premio Nobel de Medicina, reconocimiento que fue cuestionado por algunos de sus colegas. Sospechosamente, y de manera casi simultánea, también fue acusado de plagio por el Colegio de Profesores de la Facultad de Medicina de Viena. No obstante, como señalan Martínez-Mier y Toledo-Pereyra (2000: 85):

El comité del Premio Nobel emprendió una investigación de estos cargos encontrándolos todos infundados o falsos. Esto liberó a Bárány de toda culpa o responsabilidad negativa del incidente y la reivindicación pública fue llevada a cabo por escrito en un reporte a la revista escandinava Acta Otolaryngologica.

\section{Hacia una redefinición del concepto de plagio académico}

Actualmente, algunos autores mantienen la postura sobre el plagio de ideas en el ámbito académico. Específicamente, Bianchi Pérez (2016) asume esta posición y presenta como ejemplo de ideas susceptibles de plagio «una teoría o hipótesis». No obstante, tanto las teorías como las hipótesis científicas, aun cuando se originan de una idea, son mucho más que una simple representación conceptual de la realidad.

A diferencia de las ideas abstractas, las teorías científicas son construcciones que implican tanto juicios como razonamientos explicativos y predictivos que se concre- 
tan en creaciones u obras intelectuales escritas (obras literarias) y amparadas por el derecho de autor. Aun cuando no se debe generalizar, se puede afirmar que muchas de las grandes teorías e hipótesis científicas han sido plasmadas como obras escritas: artículos o libros publicados, por ejemplo, la teoría de la evolución de Charles Darwin fue plasmada en su obra El origen de las especies (1859) y algunas de las hipótesis de Mendel sobre la herencia fueron publicadas en su artículo «Experimentos en hibridación de plantas» (1865). La teoría de la relatividad general de Albert Einstein fue publicada en 1915 y los manuscritos originales están en resguardo de la Academia Israelí de Ciencias. Finalmente, las Leyes de Newton fueron publicadas en su obra Principios matemáticos de la filosofía natural (1687).

De hecho, el avance del conocimiento científico y el progreso de la academia se nutren de las obras publicadas gracias a la comunicación escrita. El conocimiento científico es acumulativo y se construye sobre la base de obras anteriores. De ahí que en los círculos científicos y académicos exista la expresión "publicar o perecer»o «publicar o morir» (Tudela y Aznar, 2013).

Además, en relación con lo planteado por Bianchi Pérez (2016), la prueba de un presunto plagio en el medio académico sería mediante la comparación de las similitudes en obras concretas: tesis, informes de investigación, trabajos de grado y de ascenso, libros y artículos publicados. Por el contrario, la prueba nunca será a través del contraste de ideas abstractas e intangibles, sino a través de la forma de expresión reflejada en los textos.

Como expresó Antequera Parilli (2010: 143), «el plagio se mide por las similitudes más que por las diferencias entre ambas obras», pero es indispensable insistir en que un alto grado de similitud entre dos obras no necesariamente implica plagio, porque para que este ocurra se requiere la copia de elementos esenciales y estructurales de una obra cuya originalidad debe haber sido plenamente comprobada.

En consecuencia, se redefine el plagio académico como una categoría del plagio literario, que consiste en la apropiación ilícita, total o parcial de aspectos sustanciales $y$ estructurales de una obra original escrita $u$ oral plasmada en algún tipo de soporte material o digital (puede ser una grabación o video), desconociendo su autoría o asumiéndola como propia.

\section{Conclusión}

Sin la intención de agotar el tema, el objetivo de esta investigación se cumplió al presentar un análisis de lo que no es plagio académico mediante el examen de objetos no protegidos por el derecho de autor, como las ideas, los hechos y el conocimiento del dominio público.

El análisis de la jurisprudencia sobre derecho de autor revela el énfasis de las sentencias en la propiedad intelectual que posee un autor por el mero hecho de haber 
creado la obra, la cual es el objeto de protección legal. Luego, para que una obra goce de protección legal, se debe probar la existencia de la misma, aun cuando esta no haya sido publicada, difundida o registrada.

La copia literal total o parcial, así como la reproducción de aspectos esenciales de cualquier obra sin la debida cita o reconocimiento de su autor, constituyen una infracción conocida como plagio. El principal requisito para alegar plagio es la existencia de la obra plagiada, sin que sea necesario, como se expresó, que dicha obra esté divulgada o inscrita en algún registro.

Otro supuesto importante para que se incurra en plagio es el carácter original de la obra plagiada, impregnado por la personalidad del autor. En el caso de una obra de escasa originalidad y novedad, resulta poco probable que sea susceptible de copia o plagio.

Un aspecto interesante observado en la jurisprudencia española es que el tutor o director de tesis no necesariamente es su coautor. Por consiguiente, se debe hacer uso lícito de cualquier contenido respetando la autoría del tutorado.

La propiedad intelectual tiene sus límites y han quedado claros los supuestos en los que no se incurre en plagio. Entre los objetos no protegidos por la legislación del derecho de autor se encuentran las ideas, los hechos públicos y notorios, así como el conocimiento del dominio público, cuyos usos lícitos se consideran excepciones de plagio académico, como ha sido señalado por legislaciones nacionales e internacionales y tanto por la doctrina como por la jurisprudencia a la que se ha hecho referencia en este artículo.

Jurídicamente hablando, en esta dirección es posible afirmar que el plagio de ideas es improcedente, y lo mismo sucede con el plagio de contenidos de autoría indeterminada que históricamente conforman el conocimiento de dominio público, por lo que se hace necesario redefinir el concepto tradicional de plagio académico mediante la exclusión del término «ideas» para referirse exclusivamente a obras concretas y materializadas, frases, párrafos, expresiones y contenidos.

No obstante, el plagio académico sí es procedente cuando se copian elementos sustanciales y estructurales de obras reconocidas como significativamente originales, en las que no solo se toma contenido, sino también la forma o estilo de expresión sin reconocer la autoría mediante el otorgamiento del crédito o la cita correspondiente.

Es muy importante difundir el derecho de autor en los círculos científicos y académicos, con el fin de evitar falsas e improcedentes acusaciones de plagio que pudiesen manchar la imagen de un autor y frenar el avance del conocimiento científico.

\section{Referencias}

Alonso Arévalo, Julio (2017). «QQué es plagio y cómo detectarlo?» Desiderata, 2 (6): 24-26. Disponible en bit.ly/38i6gfF. 
Álvarez Undurraga, Gabriel (2014). «La investigación jurídica como un instrumento de mejoramiento del proceso enseñanza-aprendizaje del derecho». Revista de Pedagogía Universitaria y Didáctica del Derecho, 1 (1): 36-57. Disponible en bit. ly/2KEsdxe.

Antequera Parilli, Ricardo (2010). «El derecho de autor en el ámbito universitario. Comentarios de jurisprudencia». Propiedad Intelectual, 13: 124-149. Disponible en bit.ly/3rcTrvG.

ArCe Gómez, Celin (2009). «Plagio y derechos de autor». El Foro, 10: 59-67. Disponible en bit.ly $/ 37 \mathrm{wVeEo}$.

ARIAs Odón, Fidias (2019). «Citación de fuentes documentales y escogencia de informantes: Un estudio cualitativo de las razones expuestas por investigadores venezolanos». e-Ciencias de la Información, 9 (1): 3-23. Disponible en bit.ly/2WvCYoi.

Astudillo Gómez, Francisco (2006). «El plagio intelectual». Revista Propiedad Intelectual, 5 (8-9): 242-270. Disponible en bit.ly/37u1b4S.

Becerra Ramírez, Manuel (2012). «El trabajo académico, plagio y derechos de autor». Dispraxis, 2: 47-171. Disponible en bit.ly/2KyMgoa.

Bianchi PÉrez, Paula Beatriz (2016). «El plagio: Implicaciones éticas y jurídicas. Especial referencia al ámbito académico». Propiedad Intelectual, 15 (19): 215-233. Disponible en bit.ly/38fgxsZ.

Cerlalc (2009). Objeto del derecho. Forma de expresión. Uso de ideas. Disponible en bit.ly/3h2Ejg4.

Desbois, Henry (1978). Le Droit d' auteur en France. París: Propiété littéraire et artistique. Eco, Umberto (2010). Cómo se hace una tesis. Madrid: Gedisa.

Joyce, Craig, Tyler Ochoa, Michael Carroll, Marshall Leaffer y Peter Jaszi (2016). Copyright Law Tenth Edition. Durham y Carolina del Norte: Carolina Academic Press.

Llopis NADAL, Patricia (2019). «Estudiantes de ciencias jurídicas y trabajos de investigación: Análisis de los derechos de propiedad intelectual sobre el TFG, el TFM y la tesis doctoral». Revista de Educación y Derecho, 20: 1-22. Disponible en bit. ly/2JbqO11.

Martínez-Mier, Gustavo y Luis Toledo-Pereyra (2000). «Robert Bárány. Cirujano, controversia y premio Nobel». Cirugía y Cirujanos, 68 (2): 80-85. Disponible en bit.ly/3r8Y7CU.

Maurel-Indart, Helene (2014). Sobre el plagio. Buenos Aires: Fondo de Cultura Económica.

Miranda Montecinos, Alejandro (2013). «Plagio y ética de la investigación científica». Revista Chilena de Derecho, 40 (2): 711-726. Disponible en bit.ly/3apUTFm.

Morales Montes, Marco Antonio (2016). «El plagio académico desde la perspectiva del derecho de autor». ESPACIO I+D, Innovación más Desarrollo, 5 (11): 104120. Disponible en bit.ly/3amGAkD. 
OMPI, Organización Mundial de la Propiedad Intelectual (1979). Convenio de Berna para la Protección de las Obras Literarias y Artísticas. Disponible en bit.ly/3axeymF.

-. (1996). Tratado sobre derechos de autor. Disponible en bit.ly/3p3w2uX.

Palazzi, Pablo (2009). La exclusión del régimen de derecho de autor de las ideas, sistemas, métodos, aplicaciones prácticas y planes de comercialización. San Andrés: Universidad de San Andrés. Disponible en bit.ly/38gokUC.

RuipéreZ, Germán y José García-Cabrero (2016). «Plagio e integridad académica en Alemania». Comunicar, 14 (58): 9-15. Disponible en bit.ly/3p3wvNJ.

SABIno, Carlos (2009). Cómo hacer una tesis. Caracas: Panapo.

Schmitz Vaccaro, Christian (2009). «Propiedad intelectual, dominio público y equilibrio de intereses». Revista Chilena De Derecho, 36(2): 343-367. Disponible en bit.ly/3myFıT6.

Sierra Bravo, Restituto (2003). Tesis doctorales y trabajos de investigación científica. 5. ${ }^{\mathrm{a}}$ ed. Madrid: Thomson.

The Harvard College Writing Program (2016). Harvard Guide to Using Sources. Disponible en bit.ly/38eLxcN.

TolLER, Fernando (2011). «Propiedad intelectual y plagio en trabajos académicos y profesionales». Revista la Propiedad Inmaterial, 15: 85-97. Disponible en bit. ly/37xEuwB.

Tudela, Julio y Justo Aznar (2013). «¿Publicar o morir? El fraude en la investigación y las publicaciones científicas». Persona y bioética, 17 (1): 12-27. Disponible en bit. ly/3mwwrVc.

UnesCo (2003). Recomendación sobre la promoción y el uso del plurilingüismo y el acceso universal al ciberespacio. Disponible en https://bit.ly/2UaT6uN.

\section{Agradecimientos}

A Craig Joyce, por haberme enviado gratuitamente su valioso libro, el que es imposible comprar en Venezuela.

\section{Sobre el autor}

Fidias Gerardo Arias Odón es doctor en Ciencias Sociales y magíster Scientiarum en Educación Superior de la Universidad Central de Venezuela. Además, es licenciado en Educación Física del ISCF «Manuel Fajardo» de Cuba. Actualmente, es profesor del Doctorado en Educación de la Universidad Católica Andrés Bello y del Doctorado en Ciencias Sociales de la Universidad Central de Venezuela. Su correo electrónico es fariasod@ucab.edu.ve. (D) https://orcid.org/00oo-0002-1786-7343. 